\title{
Communities of practice and habitus: a critique
}

\author{
Dr Alistair Mutch \\ Principal Lecturer, The Nottingham Trent University \\ Department of Finance and Business Information Systems, Burton Street, \\ Nottingham, NG1 4BU \\ Telephone: $\quad 01158484206$ \\ Fax: $\quad 01158486512$ \\ Email:_alistair.mutch@ntu.ac.uk
}

Alistair Mutch is Principal Lecturer in Information Management in Nottingham Business School at the Nottingham Trent University. He began academic life as a historian exploring rural life in Victorian England and then worked for British Telecommunications for ten years. He is interested in developing a critical realist perspective on the use of information, as well as in exploring the historical dimension of information use. He has published on, amongst other things, the current status and historical formation of welding, and the use of information by trades unions. He is currently working on a history of public house management in the United Kingdom, following a study of contemporary practices.

\section{Abstract}

Pierre Bourdieu's concept of 'habitus' is frequently drawn upon in work on learning and knowledge in organisations. However, this use is much looser than Bourdieu's emphasis on habitus as generative structure. This tension is explored in an examination of the work of UK public house managers, using the notion of communities of practice. The issues that this raises about habitus are developed through a consideration of the work of Basil Bernstein. His work indicates the value of a concept that emphasises durable dispositions to act, but such a concept needs to be embedded in a relational conception of the agency-structure divide. 
Descriptors: Bourdieu; Bernstein; habitus; communities of practice; public house managers

\section{Introduction}

This article has its origins in fieldwork on the way in which a particular group of managers used information. In the course of this fieldwork, Pierre Bourdieu's notion of habitus seemed attractive in making sense of influences on that use of information. Habitus crops up in a number of treatments of managers, learning and knowledge (Lave and Wenger 1991; Von Krogh, Ichijo and Nonaka 2000) One such context for the use of the term is work on communities of practice (Wenger 1999; Delamont and Atkinson 2001). However, in contrasting the use of the term by Bourdieu and by others some contradictions and tensions emerge. In particular, there is a tension between Bourdieu's use of the concept as a generative structure that conditions practice and the focus in the literature on communities of practice on structures that emerge from practice. This paper explores these tensions in order to consider further the value and use of Bourdieu's concept.

In so doing, we have to bring to the foreground a running sub-text. That sub-text is the way in which we employ concepts. We can, following Walsham (2001), suggest that we can use concepts in a number of ways. We can use them as sensitising devices that suggest to us areas of concern on which to focus during our investigations.

Alternatively, we can use them as structuring devices to make sense of the results of those investigations. If we use our concepts in these ways, then the way in which we use them does not necessarily have to be 'faithful' to the sources. That is, we can use familiar concepts in new ways, or take concepts from one context to another and play 
with them. Such playfulness can give us creative new insights. However, there is also a use of concepts which sees them being used in a more rigorous fashion, a fashion which rules some things in and some things out of our investigations and which means that we have to pay more attention to the logical connections between, and entailments of, the concepts we use (Stones, 1996). Such an approach means that we have to pay careful attention to our sources, making sure that we give due care to the consequences that use of a concept brings with it. Of course, such an approach runs the risk of textual exegesis, with the dangers of dogmatic and sterile adherence to the received word. However, by returning to what Bourdieu says about habitus, it is hoped to reach a balanced assessment of the value of the concept in investigations of contemporary managerial practice.

At the same time, it is hoped to present a picture of managerial use of information in one particular group of managers. The concept of communities of practice is used to present the world of this group of managers. We look at a variety of potential communities of practice, considering the boundaries between each. This enables us to point to the lack of treatment in the literature of dispositions that managers bring into these communities from their life experience and to suggest that habitus might be a fruitful means of pursuing these. This leads us to a brief exposition of Bourdieu's use of habitus, showing how central it is to his thought. The characteristics as Bourdieu sees it of a durable, unconscious and embodied set of transposable dispositions are compared to use by others and shown to reveal a tension as outlined above. However, such a tension in turn suggests some problems with habitus itself, notably the difficulty of dealing with change and the vague nature of the concept for use at more detailed levels of analysis. These weaknesses lead us to an examination of the work of 
a rather less well-known writer, the British sociologist of education Basil Bernstein. The parallels between his work and that of Bourdieu are explored, with the suggestion that his work provides ideas for more detailed examination of the problemmatic suggested by Bourdieu. The way in which this work has been applied to managers is briefly explored in order to point to some difficulties. The article closes by suggesting some implications of the discussion for further research. Throughout, the aim is to use the field material to illustrate the potential value of, and the difficulties involved in applying, theoretical notions. As well as helping us understand the case material presented, the objective is also to contribute to the debate on influences on learning in organisations.

The research site for this work was the United Kingdom licensed retail sector. This sector grew out of the brewing industry and comprises the complex of public houses, bars and other outlets that are licensed by the State to sell alcohol for consumption on the premises. Whilst many of these outlets are owned by individual business people, and many others are run by tenants, an increasing proportion is owned by large national companies and run by salaried managers (Mutch 2000a). Such managers form the focus of attention of this research. The research was set in the North East of England district of Whitbread Inns, a division of Whitbread that at the time of the research in 1999 owned 1700 outlets across the country. (The division and company no longer exist in the same form, the managed houses having been sold off together with most of the other public houses in 2000.) The research involved interviews with 25 individuals, most of them pub managers but some area and other managers. These were supplemented with analysis of company documents, observation of a range of meetings and a survey to capture basic data unavailable from company records. The 
impetus behind the research was work in the area of information literacy (Mutch 2000b). The focus on habitus, therefore, was an emergent one and in this sense this article is a piece of reflexive sociology which does not aim to present fully formed research solutions but to reflect the contradictions and tensions that emerged in practice.

\section{Communities of practice and the pub manager}

When we consider pub managers in the context of communities of practice, a number of potential communities suggest themselves. The following discussion uses four such groupings - the functional group, the local group, the manager and staff in the pub and the manager with customers - to both introduce and elaborate on the working domain of the pub manager and to frame the treatment of habitus. In each case we trace out the major contours of the suggested community of practice; each could be the focus of detailed exploration, but this is not the concern of the present treatment.

The first such group is that created by the company itself, which we will call 'functional groups'. Managers are grouped into areas of between 14 and 18 houses, each headed by an area manager. The smaller groups tend to be allocated to either area managers with other responsibilities (such as training) or more recent recruits. Companies are keen to encourage the sharing of practice between managers within these groups, having devoted some effort to changing the traditional role of the area manager (Preece, Steven and Steven 1999; Mutch 2000c). Historically the pubs were run in considerable detail by area managers, who used information about stock levels 
and other disciplinary mechanisms (such as personal style) to control their house managers (Cooper 1970; Berkeley 1955). In the words of one area manager who operated in the 1960s and 70s, when asked about letting house managers know about how much profit they were making: 'Right, knowledge is power so the district manager wouldn't take that back down to the house.' (Alf Cross, area manager, Bass, 1965-1980). In current practice, house managers received detailed information and area managers were expected to discuss this, seeing their role as encompassing development and facilitation of change in a much more cooperative fashion. House managers in the fieldwork had noticed and welcomed this change of style. However, there were considerable limits on the functional groupings as communities of practice. The groupings were based on a variety of considerations: type of house, roughly equivalent turnover, geographical location. This meant that managers were often spread over a considerable geographical area, making contact other than by telephone difficult (Mutch 2000c). For Susan

We don't really have - apart from at area meetings - we don't really have a lot of contact unless you're good friends with someone. We don't really have a lot of contact and I don't have a lot of time. I have Sundays off which is - ... everybody has Wednesday off. So if I went up to visit somebody else they'd be working anyway and I have Sundays off because it's the only day I get to spend with my son because he's at college all week. But I've got two friends who've got pubs the other side of Sheffield and they come down here on their day off and have a chat and what have you, but apart from that it's just people in your own area (Susan Milner, house manager, single). 
In addition, functional groups changed composition rather too frequently for stable relationships to be established, not least because of a fairly regular turnover of area managers. Area managers, in turn, tend not to be drawn from the ranks of house managers, but from auditors and stock takers. Despite the attempts of the companies, then, there are difficulties in regarding functional groupings of house managers as successful communities of practice.

An alternative sharing of practice took place in the networks of house managers that took two forms. One was that in the locality, where there might be contact and support between managers whose houses fell into different area teams. For Susan, this was another manager who

If you ever get problems you just phone John up. But when it comes to things like margins, GP's, anything to do with menus, really anything to do with the business and he's spot on. ...People have said, I get really stuck, phone John up, and John is one of these, even if he's still on the phone to you at four o' clock in the morning he'll not stop until you understand it. Then he'll probably turn up in your pub the next morning to see if there's anything else he can do. He's very good (Susan Milner).

This local support was clearly limited by the existence of houses from the same company within reasonable distance. Contact with house managers or tenants from other companies tended to be limited, especially with the atrophy of licensed trade organisations in many areas. A more potent network was with trainer managers, 
where help and advice was sought: 'So I think yes me and Andy are very similar and because he's been here, poor lad, poor lad. I'm the downfall of his career.' (Paul Potter, trainer-manager, married couple). However, this contact was often, again, at some physical distance. Such spatial considerations mean that powerful influences on practice were those present during the working day: staff and customers.

All the houses employed staff to different levels, generally on a part time basis. These employees were enormously important sources of information about both customers and competitors and the company encouraged the development of this resource. Training schemes were devised which had a crucial role for the house manager in staff development, underpinned by elaborate reward schemes (Arkin 1996). This potential community of practice could develop in two ways. In some cases, the transfer of information seemed to be fairly one way, with little attempt to secure deeper involvement, a process explained by the managers as due to the lack of commitment of part-time staff. As Joanne argued:

your greatest pool of ideas, in a sense that my employees are my greatest resource. I know that I have, we try to talk about lots of different ideas but my particular staff, and this is going back some time, I didn't seem to get much back from them. It's now that I'm sort of thinking about why. At the end of the day it's mainly because some of the staff I have employed... I think it's very difficult for any house manager to try and find anybody that isn't behind that bar just for the fact that they need a job (Joanne Slater, single female manager). 
In other cases, however, there were attempts to develop deeper understandings of practice. For example, the task of supplying competitor information was regarded as a chore by many managers, to be completed with more or less enthusiasm by themselves. Some, however, sought to involve staff directly, as in the following:

They find it very interesting, you know, we get, they go in pairs not on their own, so they don't find it uncomfortable. We give them some money for a drink, you know, some drinks or something and I'll look after the bar and I'll say I want you to do a survey for me. There's a sheet of paper and three pubs, the Jockey, the Star and the Earl Grey and I want to know what products they sell, how they're selling it. So that's product knowledge they're fetching back (Margaret Stuart, manager, married couple)

It was noticeable that these attempts involved either a single female manager or the female partner of a married couple, a distinction that we will return to. However, we have also to consider the potential for house managers to be involved in another 'community of practice'; that with their customers.

To call this a community of practice might seem to be stretching an already elastic concept a little too far. However, it is useful to consider the way in which customers in this case intrude deeply into the working environment of the manager. They do so perhaps in ways that are not paralleled by other managers and mean that managers are deeply embedded in their 'environment'. Indeed that environment comes into the work setting every day. And these are not abstract customers, but embodied individuals who may have been using the house for many years. Indeed, the social 
setting of the pub is one that is open to constant negotiation and renegotiation between manager, staff and customers (Smith 1981). The clearest evidence of a clash here comes with the use by the company of 'mystery visitors' who check that laid down quality standards are being met. League tables are drawn up based on scores from such visits and form an important part of discussions with area managers. The clash comes when a centrally derived standard of practice, such as always asking a customer what she or he would like to drink, is brought up against the local knowledge that a certain regular always has the same drink in the same glass and is offended if asked to change. We can locate the manager on the boundary between two sets of practice, but the pull of the locality is strong. It is this pull of the local that we can see reflected in the following discussion at an area meeting:

Why does it have the actual wage written on it so every member of staff knows exactly what everyone else is getting paid? You'd end up having to change your staff every week.

Signing sheets should be individual or signed so that people can't see what other people are getting.

That would never happen in a steelworks or something like that, you would never ever...

It shouldn't need to happen basically. It shouldn't need to happen. They shouldn't need to sign for it. 
That would never ever happen in a factory. [my emphases]

What is instructive here is the comparisons made to steelworks and factories, comparisons that relate to the local conditions of these managers, but that might point to interpretive schemes that might go beyond these being simply reference points drawn from the local context. Certainly, we can attribute such comparisons to such a context, or to individual biographies, but there seems to be something more than this that Bourdieu's notion of habitus might help with. Others who have used the notion of community of practice certainly seem to agree. For example, in their discussion of the socialization of doctoral science students, Delamont and Atkinson, argue that 'Tacit knowledge is grounded in knowledge and skills acquired through membership of a particular social group. It includes the taken-for-granted and embodied competence of habitus' (Delamont and Atkinson 2001:101). The embodied aspect of habitus is indeed attractive in the context of our house managers, who spend much of their day in embodied practice, with both staff and customers. However, there are issues about the relationship between communities of practice and habitus that need to be explored. It is this exploration that forms the basis of the next section, but put simply the tension is this. Bourdieu's notion of habitus is not just about embodied forms of practice, but modes of thought that are unconsciously acquired, that are resistant to change and are transferable between different contexts. The communities of practice literature, by contrast, focuses on changes brought about through practice itself. If the use of habitus is a more general one (and the word is not, of course, exclusively that of Bourdieu (Smith 2001)) then we could argue that communities of practice develop their own embodied forms of practice. However, this does not seem to be the sense in 
which Bourdieu uses the term. To explore this tension, it is worth looking in more detail at Bourdieu's use of habitus.

\section{Bourdieu and habitus.}

The notion of habitus has been a central one in Bourdieu's massive oeuvre. A recent formulation that can act as a starting point for our discussion is the following:

The conditionings associated with a particular class of conditions of existence produce habitus, systems of durable, transposable dispositions, structured structures predisposed to function as structuring structures, that is, as principles which generate and organize practices and representations that can be objectively adapted to their outcomes without presupposing a conscious aiming at ends or an express mastery of the operations necessary in order to attain them. Objectively 'regulated' and 'regular' without being in any way the product of obedience to rules, they can be collectively orchestrated without being the product of the organizing action of a conductor (Bourdieu 1990:53; emphasis in original).

If we explore this statement, we see, firstly, an explicit link between patterns of thought and social conditions. Particular forms of social condition produce particular forms of habitus. The habitus is in turn not such much a content as a set of principles, principles which are embodied, expressed in the hauteur of the aristocrat or the stance of the peasant. Rather than a focus on particular contexts in which principles can be employed, the emphasis is on the way in which a similar set of principles is employed 
across contexts, are 'applied, by simple transfer, to the most dissimilar areas of practice' (Bourdieu 1986:175). A crucial factor in this application is then whether they are appropriate to the particular rules of the game. Bourdieu is particularly concerned to stress the practical mastery of the rules of the game and the effortless performance of rules without the recognition that such rules are being followed. The rules emerge from the ebb and flow of practice and are inherent in the relations that operate in a particular field. 'There is,' argues Bourdieu, 'an economy of practices, a reason immanent in practices, whose 'origin' lies neither in the 'decisions' of reason understood as rational calculation nor in the determinations of mechanisms external to and superior to the agents' (Bourdieu 1990:50). However, the ability to employ the appropriate strategies depends on the tacit acquisition of generative principles that depend on social position. Those from different social conditions will tend to respond in the same way, because of the objective conditions of existence that they share (Bourdieu 1990:58). Their early experiences will be crucial in determining their future responses, as they will tend to react to new experiences by assimilating them to the generative principles they acquired (Bourdieu 1990:60). The focus on practice is clearly attractive to those developing the notion of communities of practice (Wenger 1999:281 note 6) but we need to recognise that for Bourdieu habitus is prior to practice and regulates it. This seems to give problems for conceptions that privilege the development of modes of operation through practice. If habitus, as Bourdieu has it, is acquired at an early stage in an unconscious fashion and is resistant to change then the issue is the interaction between habitus and practice, rather than its creation through practice. 
Habitus is initially attractive in considering our pub managers not only for its focus on embodied practice, but also for its attention to their social origins. The dramaturgical aspects of the house managers' practice are ones recognised and valued by many managers. Each session is a performance to be carefully orchestrated by them. As Paul explains:

Some days you think to yourself, 'oh bloody hell I've got work again today' and it becomes a drag - and then you walk in that evening at eight o'clock the pub, you know your pub's buzzing, people are enjoying it and it clicks you on straight away (Paul Potter).

For the company, there may be evidence, drawn from customer surveys, that the landlord should take a more backstage role, but this is resisted in concrete practice by many managers. In Paul's direct terms 'It's crap, the landlord should be seen in every pub.' Elaborating on this, Doug argues strongly that his actions have direct consequences for success:

I mean, I do the bar normally three until six and the crowd that come in they come and see me and we have them all sat behind the bar and everybody knows each other and they have a laugh. We've got a local tax inspector there haven't we? We've got a couple of accountants and we've got a couple of lads that work on a building site and what have you and I can relate to all of them or they can all relate to me. We all get involved and we have a laugh like, you know, and we have a couple of beers with them and that's most probably put five thousand a year on my profit you know. If I just worked to 
the policy which they want me to do, you know, 'would you like Heineken or Stella?' and all stuff like this, they wouldn't come in here (Doug Jess, managers, married couple).

On top of this embodied practice are the social origins of many managers, who are not only in daily contact with their 'audience' but are also a product of it. Traditionally, the move into pub management has been a 'career' change, generally happening from the mid-30s onwards. Many managers were drawn from the ranks of those whose initial career choice forced such a switch - notably the services and sport (Ferguson 1999). Others came from predominantly manual craft backgrounds, often having experienced a variety of occupations. Mary contributes both her and Doug's trajectories: 'No qualifications at all. You've done this work on building sites and foundry. You worked in a foundry didn't you? I was a secretary, well I was a receptionist secretary for five years and then I left to have a baby. Then I worked in a supermarket on the checkout, you know, dealing with people (Mary Jess, manager, married couple). Such recruits often have little or no formal education: their skills have been acquired in practice and they put their focus on the necessity of such skills (Mutch 2001). However, this situation is subject to change and such changes suggest problems with the use of habitus.

Part of our problem rests with the level of our analysis. Bourdieu's use of habitus has to be seen in the context of his broader project, "whose ambition is not simply to combine, articulate or join structure and agency but, more fundamentally, to dissolve the very distinction between these two seemingly antinomic viewpoints of social analysis' (Wacquant 1993:3). This leads to analyses at a broad level of generalisation, 
but problems occur when seek to apply the ideas at a more detailed level of analysis. Before examining such issues, however, and given the central place which habitus occupies in Bourdieu's project, it is necessary to recognise a more general critique. This has seen accusations of a functionalist approach, in which social practices are explained by the effects they produce (Callinicos 1999; de Certeau 1984). This form of circular argument allows little purchase on the levers of change. Whilst Bourdieu's concern has been to incorporate active, practical action into his perspective, the focus has tended to be, argues Fowler, on the dominant classes. Habitus, she contends, 'possesses a fatalistic consequence, particularly acute in depicting the subordinate class, whose habitus is simultaneously defensive and the product of a colonised sense of inferiority' (Fowler 1997:4). So whilst valorising particular aspects of working class thought and culture in opposition to dominant codes, it allows little space for their generalisation as a force of change. Language is seen as a powerful socialising force, with oppositional sites being restricted to arenas such as the prison and the pub. The notions that Bourdieu adopts in respect of patterns of thought, on this argument, are better at explaining transmission and reproduction than at explaining change. To summarise crudely: if patterns of thought are established through tacit acquisition at an early stage, if such patterns of thought are durable and transferable, and if they reflect and reproduce existing patterns of social structure, then how are they to change? If the existing social structures are made possible through patterns of thought which have their inevitability built in to the very bodily positions adopted, how can they be changed, other than by exogenous shocks? (Douglas 1996:160). How can patterns of thought emerge which challenge existing modes of thought, at a macro level, or how can individuals, at a micro level, escape the habitus which they have acquired? How, in LiPuma's (1993) words, can we explain Bourdieu? How is it that a 
postman's son from a remote peasant area of France can ascend to the heights of Parisian academic life and proceed to write in such detail about the academic habitus?

This is to raise issues with change at an individual level. There are also changes, changes that we can track in the domain of the pub manager, which might be thought to challenge the links between conditions of labour and dispositions to think and act. Calhoun (1993:85) argues that 'The roles of information technology, very large-scale administrative organizations, and impersonal markets are all important, both in their own right and as factors militating for basic changes in habitus and fields.' In the context of our pub managers, the spread of IT based information systems has seen, as in many industries, the growth of data available to the pub manager (Baker, Wild and Sussman 1998). Each manager received a monthly profit and loss account for the house and was expected (in theory) to use it to plan their activities. In turn this report was based on the electronic gathering of data based on electronic point of sale equipment. In Lash's (1993:204) terms 'This means that agents must be reflexive in taking into account the very rules and resources of the productive situation itself.' Such changes, also noted by others (Zuboff 1988; Earl 1994; Lokjine 1986), are part of changes in recruitment practices that in turn colour the communities of practice that pub managers operate in. Companies have turned their attentions to new pools of recruits, focussing their attention on both graduates and on part time staff (Mutch 2001). The latter route is particularly important in the expansion of the number of single female managers. The result has been a much more heterogeneous workforce. One implication of such changes, changes which lead both to changing structural conditions of work and the potential for much greater change during an individual's life, is that the notion of a basic, 'foundational' habitus might be harder to sustain. As 
an illustration of the sort of difficulties we can get into, it is interesting to examine Brubaker's (1993) essay on 'Social Theory as Habitus'. In this he argues for the existence and necessity of a sociological habitus, a collection of dispositions which encourage one to see the world sociologically. A prime component of this habitus is, or should be, a conscious reflection on these dispositions. Of course we have already seen that habitus is distinguished by its early acquisition, in largely tacit fashion. As a result it is both embodied and largely unconscious. It represents a series of interrelated durable and transposable generative practices which are generalised across contexts. Recognising this leads to Brubaker to argue for a stratified habitus: 'The sociological habitus, then, is a tertiary or higher-order habitus, overlaid on, transforming without superseding, a primary familial and a secondary scholastic habitus' $(1993: 226)$. But if this is the case, do we not lose what seems to be central to the concept, the durability and transferability of practices? We risk the creation of one, two, many habituses and so splintering the concept beyond recognition. It could be a cogent argument that the growth of instrumental reason weakens the grasp of the primary habitus and increases the need for abstract reasoning - as Calhoun (1993) seems to be arguing. One response in these circumstances is to reject habitus in Bourdieu's sense. However, our observation in the case of the pub managers is that habitus in the sense of durable dispositions to act has something to offer, if we can find more precise ways of conceiving of its formation and impact. Such ways might in their turn help us examine the impact of previous experience on the ability to negotiate identity and meaning that plays a central part in Wenger's (1999) conception of communities of practice. 
The issue, then is trying to think through this previous experience in ways that are less vague than Bourdieu's usage, but still retain the emphasis on tacit acquisition and durable existence. We can draw upon Bernstein's critique here:

Habitus is described in terms of what it gives rise to, and brings, or does not bring about. It is described in terms of the external underlying analogies it regulates. But it is not described with reference to the particular ordering principles or strategies, which give rise to the formation of a particular habitus. The formation of the internal structure of the particular habitus, the mode of its specific acquisition, which gives it its specificity, is not described. How it comes to be is not part of the description, only what it does. There is no description of its particular formation. (Bernstein 1996:136)

This indeterminacy of concepts is argued by some to be a strength of Bourdieu's thought, by others to be a passing irritation that has to be lived with (Delamont, Nash and Apple 1993:321). The problem comes with operationalisation, with uses being as a convenient form of shorthand or as a theoretical gloss that explains little (Reay 1995; Corsun and Costen 2000). Such uses seem to fall under Stones' critique when he suggest that 'Characterising labels are often attributed to individual agents, or to supposedly like thinking cabals (aggregate groups), in order to fix the theorist's interpretation more firmly and to camouflage the lack of appropriate evidence.' (Stones 1996:107). If such an accusation is not to stick, are there ways of rescuing habitus? The following section suggests that there are, if we place it in the context of a rich and complex ontology and if we develop its scope by drawing upon the ideas of others. 


\section{Writing grammars for habitus?}

Fittingly, the first of these others that we draw upon is Basil Bernstein (Atkinson 1985; Sadovnik 1995). Fittingly, because of a shared interest in education (Bourdieu and Passeron 1977; Collins, 1993) and a brief period of shared workspace. There are other parallels (Archer 1983; Harker and May 1993), but Bernstein's work, compared to that of Bourdieu, has had relatively little influence outside the sphere of educational studies (with the important exception of those looking at changes in capitalism from the perspective of sociolingistics such as Gee (1996) and Gee, Hull and Lankshear (1996)). Accordingly, a brief outline of his work is in order. Bernstein's work originates from his experience in teaching young apprentices in the East End of London. His first explanation of the discrepancies in performance between those from different social backgrounds revolved around the distinction between 'restricted' and 'elaborated' codes (Bernstein, 1971). The restricted code was related to a specific context, with a use of language which rested heavily on shared assumptions about that context. It would therefore be restricted in the terms and concepts used. An elaborated code, by contrast, would be appropriate to contexts where such assumptions were not shared and where language would have to make explicit its claims. Some speakers, Bernstein argued, had access to two codes and such access was crucially related to social class. For the social division of labour gave rise to conditions which favoured and reinforced a restricted code. Such codes are entirely appropriate to some contexts, but not to others. Those who only have access to a restricted code are therefore at a disadvantage when an elaborated code is required. However, the issue is not that one code is inherently 'better' than another, but that the performances produced by one are more appropriate in certain circumstances than others. Centrally, for Bernstein, such a circumstance was the school and his attention turned to the ways in which the school 
could modify such orientations to meaning. Restricted or elaborated meanings were initially acquired, he argued, through largely tacit modes, chiefly in the family. The existence of such modes of acquisition was powerfully demonstrated in the work of Hasan (1995) in her analysis of large volumes of natural speech. If an orientation to meaning were to be acquired in the home that was legitimated and encouraged by the official institutions of education, then pupils from such a background would be at an advantage. Bernstein's focus therefore shifts into the school and the analysis of the pedagogic process (Bernstein 1977)

The work of Bernstein and his collaborators supplements Bourdieu's work in a number of ways. It reinforces through some detailed empirical work (Morais, Fontinhas and Neve 1992; Daniels 1995) the emphasis on unconsciously acquired dispositions that profoundly affect subsequent performance. This work has produced further elaboration which makes it possible to specify in much more detail how these dispositions might be formed. Indeed, Bernstein has suggested his notion of 'code may be regarded as an attempt to write what might perhaps be called pedagogic grammars of specialized habituses and the forms of their transmission which attempt to regulate their acquisition' (Bernstein 1990:3). (What Bernstein means by code is as follows: "A code is a regulative principle, tacitly acquired, which selects and integrates: (a) relevant meanings (b) forms of their realization (c) evoking contexts" (Bernstein 1990:14).) Finally, the scope of these ideas has been broader than the perceived focus of Bourdieu on elites. Much of Bernstein's work has been on changes in the new middle class. This has given rise to an interesting application of his work in which Savage, Barlow, Dickens and Fielding (1992) have drawn on Bernstein's notion of an 'invisible pedagogy' to explore differences between managers. An 
invisible pedagogy is one that stresses individual development and lacks clear rules for measuring achievement. In such a pedagogy, the rules that help us recognise particular contexts as requiring the application of a particular performance are not clearly specified, but are recognisable by those from a particular background. We can distinguish such 'recognition rules' from rules which govern the 'realisation' of competent performances. Work on these rules in a school setting argues that whilst realisation rules can be acquired and modified by particular pedagogical strategies, recognition rules seem to come from outside school. An invisible pedagogy is that, argues Bernstein, favoured by the professional fraction of the new middle class that is associated with 'progressive' forms of education. In this, argue Savage et al, it tends to favour that fraction of the managerial and professional class that has access to stores of cultural capital and against what we could broadly term 'operations' managers - into which latter category our pub managers would fall. That is, Savage et al (1992:128) identify the latter grouping with a 'stolid 'undistinctive' - or just plain boring - lifestyle' (a distinction that has some parallels with the work on food consumption by Warde, Martens and Olsen (1999) that draws on Bourdieu for its categories). Again, Savage et al's work is at a rather broader level of analysis than the individual organisation and it could be criticised for some confusion in its categories. (The problem is that their 'professional' grouping includes managers in, for example, marketing and personnel, who would be grouped with pub managers and other operations managers in occupational classifications. In other words, like is not being compared with like) However, their work is suggestive of a need, as we have argued above, to be careful about treating managers as a homogenous group and to explore their social origins. Given the origins of the distinctions that Bernstein draws, it might be rather easier to apply his notions of rules of recognition and realisation to issues of 
managerial education and development (Mutch 2002), but one would suggest that any body of work that seeks to develop a social theory of learning, as does the communities of practice literature, ought to look carefully at what he has to offer.

Bernstein's work, then, offers ways in which we might connect the rather slippery and vague categories of high theory with the detailed investigation of concrete situations (Stones 1996). However, we have to recognise a major criticism that parallels the criticism offered of Bourdieu above: that his work emphasises reproduction over transformation. Bernstein's argument would be that the possibilities of change are built in to tensions in the classification system itself. That is, classification schemes have to deal with the thinkable and the unthinkable, but in delineating a class of phenomena that are unthinkable, they allow the possibility of those things being thought by those with access to the code. Hence the importance of the acquisition of the rules which allow agents to produce elaborated performances, for these allow them to produce oppositional arguments. Classification rules, therefore, which reflect organisations of power in society, contain the seeds of their own downfall, if oppositional agents can acquire the rules by which to subvert the code. However, quite how they do this is problematic. Bernstein is clear in arguing, for example against Foucault's formulation of discourse, that there is a place for agency and that his concept of the code does not determine human action (Bernstein 1990:6). He suggests at one point that oppositional codes can emerge from the activities of organisations such as trade unions (Bernstein 1990:111), although precisely how, given the tacit acquisition of rules at an early stage, is not clear. The problem is expressed more clearly in the following: 
The successful have access to the general principle, and some of these - a small number who are going to produce the discourse - will become aware that the mystery of discourse is not order, but disorder, incoherence, the possibility of the unthinkable. But the long socialization into the pedagogic code can remove the danger of the unthinkable, and of alternative realities (Bernstein 1996:26)

So only those who have undergone a long pedagogic process can unlock the mysteries of the code. But having the keys to the code does not mean that they will be used, for we will have forgotten why we have been striving to find them. The working class is condemned to reproduce their position in the existing scheme of things, for they only rarely enter the long process. But the middle class, too, will reproduce their position for they cease to think the unthinkable. The process of change seems to be dependent on changes in the social division of labour. What we lack is a sense of active and creative agency, of agents operating with free will in conditions that are not of their own choosing but which they can transform (or reproduce) by their activity.

One source for such a perspective, mentioned on a number of times in passing by Bernstein, is Paul Willis' (1977) work on the opposition of working class lads to schooling. Willis argued that their opposition is a positive act of resistance, which builds on alternative conceptions of work that are deeply implicated in notions of masculinity and manual labour. Some of these children may well, to use Bernstein's concepts, recognise the context. Some may also possess the rules to realise a competent performance, but they choose not to, in solidarity with an oppositional concept. This is far from all gain, of course. At the heart of this opposition is a crippling opposition to mental labour, formed by the attachment to masculinity that 
gives the resources for opposition but also prevents the opposition being fully realised (Thompson 1988). However, what is important about this account is its focus on agency and the possibility of change. Of course, Willis' work was concerned with white, working class boys; in our case, what seems interesting is the difference between what we might style 'traditional' approaches to the use of information, typified by a view of information as a static product and approaches which take a more 'processual-relational' (to use Watson and Harris' (1999) terminology) view. The latter seemed in the fieldwork to be associated either with female single managers or managing couples in which the woman took an equal role in the running of the house. We might in this case want to set this in the context of the strong identification of male managers with their traditional customer base (Smith, 1981) In this setting, it is women that are in the peripheral locations, operating on the boundaries. Perhaps these locations enable them to escape the conditionings of the habitus that receive reinforcement in the case of their male counterparts in day-to-day encounters and so promote a localised set of understandings?

\section{Conclusion}

Drawing upon the resources offered by Bourdieu and Bernstein might seem out of proportion to the examples offered by our pub managers, but their notions are useful in taking our investigations further. In turn, trying to apply the concepts drawn from their work points to a need for clarification and care in use. What, then, does habitus offer us in the context of managers and their practice? If we see theory as sensitising us to aspects that require our attention, then habitus suggests that we need to pursue the social and educational origins of our chosen group of managers in order to 
examine their effects on current practice. In the case of our pub managers, this reveals the existence of two broad groups of managers - those recruited in the traditional manner from the (predominantly) male skilled working class and those from a much more heterogeneous group in which women play a more important part. This suggests that interesting light can be shed on practice by looking at the antecedents to practice, but in turn such a focus suggests a tension with the use of a notion like habitus. This tension only exists if we are using habitus in a particular sense, in the sense that Bourdieu uses it. If we regard concepts as devices to play with, ways in which to think differently, then this distinction might be thought to be unimportant. However, if we wish to take Bourdieu's concept in the context of his overall work, then we need to do so recognising the main characteristics of his use of the term, characteristics that are given some support by the rather more detailed work of Bernstein and associates.

These are that the habitus is related to the social conditions of its production, that it is unconsciously acquired, that it is durable and embodied, and that it transcends different social circumstances to produce characteristic dispositions to act. In Wenger's terms it is a 'generative infrastructure' which has to be contrasted with the focus in his concept of communities of practice of habitus as 'an emerging property of interacting practices' (Wenger 1999:96). For Wenger, experience gained outside a particular community of practice is important, but it can be modified by that community of practice. Indeed, he argues, 'we engage in different practices in each of the communities of practice to which we belong. We often behave rather differently in each of them, construct different aspects of ourselves, and gain different perspectives' (Wenger 1999:159). Again, we can see the tension between this perspective and Bourdieu's emphasis on dispositions to act in very similar ways in very different circumstances. This focus on knowledgeable actors is one that appears in Giddens 
(1991), whose resolution of the agency-structure dilemma in structuration theory is influential in Wenger's treatment (1999:281, note 4). Bernstein, by contrast, is concerned that such a focus, which he sees as having more general roots in the work of thinkers such as Chomsky and Piaget, emphasises 'an in-built procedural democracy, an in-built creativity, an in-built virtuous self-regulation. And if it is not in-built, the procedure arise out of, and contribute to social practice, with a creative potential'. Such perspectives, he argues, mean that we pay. 'the price of abstracting the individual from the analysis of distributions of power and principles of control which selectively specialize modes of acquisition and realizations' (Bernstein 1996:58). The problem with the approach taken by both Bernstein and Bourdieu, by contrast, is that they tend towards a sense of fatalism and an inevitable reproduction of existing patterns of thought and action.

The resolution of this tension might be sought in approaches that emphasise not the either/or of agency and structure, but the both/and, recognising not only their mutual constitution but also the need to examine the inter-relationships between them (Archer 1995; Willmott 1999; Carter and Sealey 2000). Such an approach could be applied to the notion of communities of practice, examining the relationships between the work of identification and negotiability that are supplied by them and those that actors bring with them. This is to argue that multimembership is not necessarily a resource that translates into different perspectives. There are factors, and something like habitus is one of them, that condition the extent of difference between different contexts. The analytical interest lies in the extent to which such dispositions is challenged by and altered by different practices, or to what extent it remains immune to such influences. The notion of boundary here in the case of our pub managers seems fruitfully to apply 
to women as being those who in these circumstances are crossing the boundaries and who are able to negotiate new ways of knowing within their communities of practice. This in turn might usefully be related to changes in the broader economy that, Cameron (2000) argues, can be seen as privileging ways of talking and acting that have come to be associated with women.

\section{Acknowledgements}

My thanks to participants, particularly Hugh Willmott, in a workshop on managing knowledge at Keele in 1999 for comments on a paper that marked my initial interest in Bourdieu and Bernstein. My thanks also to the referees for their insightful comments given in a very helpful fashion. The fieldwork for this article was supported by award R000222881 from the Economic and Social Research Council.

\section{References}

Archer, Margaret

1983 'Process without system'. Archives Europeenes de Sociologie 24(4): 196-221.

Archer, Margaret

1995 Realist social theory: the morphogenetic approach. Cambridge: Cambridge University Press.

Arkin, Anat

1996 'Pulling ahead of the pub crawlers'. People Management 2(8): 36-38.

Atkinson, Paul

1985 Language, structure and reproduction: an introduction to the sociology of Basil Bernstein. London: Methuen.

Baker, Michael, Martin Wild, and Silvia Sussman 
1998 'Introducing EPOS in Bass Taverns: a report of the case and an exploration of some of the issues'. International Journal of Contemporary Hospitality Management 10(1): 16-23.

Berkeley, Tom

1955 We keep a pub. London: Hutchinson.

Bernstein, Basil

1971 Class codes and control volume 1: theoretical studies towards a sociology of language. London: Routledge \& Kegan Paul.

Bernstein, Basil

1977 Class codes and control volume 3: towards a theory of educational transmissions. London: Routledge \& Kegan Paul.

Bernstein, Basil

1990 The structuring of pedagogic discourse volume IV class, codes and control. London: Routledge.

Bernstein, Basil

1996 Pedagogy, symbolic control and identity: theory, research, critique. London: Taylor \& Francis.

Bourdieu, Pierre and Jean-Claude Passeron

1977 Reproduction in education, society and culture. London: Sage.

Bourdieu, Pierre

1986 Distinction: a social critique of the judgement of taste. London: Routledge.

Bourdieu, Pierre

1990 The Logic of practice. Cambridge: Polity.

Brubaker, Roger 
1993 'Social theory as habitus'. in Bourdieu: critical perspectives C. Calhoun, E. LiPuma and M. Postone (eds.), 212-235. Cambridge: Polity.

Calhoun, Craig

1993 'Habitus, field, and capital: the question of historical specificity'. in Bourdieu:

critical perspectives C. Calhoun, E. LiPuma and M. Postone (eds.), 61-88.

Cambridge: Polity.

Callinicos, Alex

1999 Social theory: a historical introduction. Cambridge: Polity.

Carter, Bob and Alison Sealey

2000 'Language, structure and agency: what can realist social theory offer sociolinguistics?' Journal of Sociolinguistics 4(1): 3-20.

Cameron, Deborah

2000 'Styling the worker: gender and the commodification of language in the globalized service economy'. Journal of Sociolinguistics 4(3): 323-347.

Collins, James

1993 'Determination and contradiction: an appreciation and critique of the work of Pierre Bourdieu on language and education'. in Bourdieu: critical perspectives. C. Calhoun, E. LiPuma and M. Postone (eds.), 116-138 Cambridge: Polity.

Cooper, Derek

1970 The beverage report. London: Routledge \& Kegan Paul,

Corsun, David L, and Wanda M Costen

2001 'Is the glass ceiling unbreakable? Habitus, fields, and the stalling of women and minorities in management'. Journal of Management Inquiry 10(1): 16-25.

Daniels, Harry 
1995 'Pedagogic practices, tacit knowledge and discursive discrimination: Bernstein and post-Vygotskyian research'. British Journal of the Sociology of Education 16(4): 517-532

de Certeau, Michel

1984 The practice of everyday life. Berkeley: University of California.

Delamont, Sara, Roy Nash, and Michael W Apple

1993 'Review symposium: the work of Pierre Bourdieu'. British Journal of the Sociology of Education 14(3): 315-325.

Delamont, Sara and Paul Atkinson

2001 'Doctoring uncertainty: mastering craft knowledge'. Social Studies of Science 31(1): $87-107$

Douglas, Mary

1996 Natural symbols: explorations in cosmology. London: Routledge.

Earl, Michael

1994 'Shorko Films SA'. in Strategic information systems, a European perspective C.

Ciborra and T. Jelassi, (eds.) 99-112. Chichester: Wiley.

Ferguson, Alex

1999 Managing my life: my autobiography. London: Hodder \& Stoughton.

Fowler, Bridget

1997 Pierre Bourdieu and cultural theory: critical investigations. London: Sage.

Gee, James

1996 Social lingusitics and literacies. London: Taylor and Francis.

Gee, James, Glynda Hull, and Colin Lankshear

1996 The new work order: behind the language of the new capitalism. St Leonards, Australia: Allen \& Unwin. 
Giddens, Anthony

1991 Modernity and self-identity: self and society in the late modern age. Cambridge: Polity.

Harker, Richard and Stephen May

1993 'Code and habitus: comparing the accounts of Bernstein and Bourdieu'. British Journal of Sociology of Education 14(2): 169-178.

Hasan, Ruqaiya

1995 'On social conditions for semiotic mediation: the genesis of mind in society'. in Knowledge and pedagogy: the sociology of Basil Bernstein. A. Sadovnik (ed.), 171-196. Norwood, NJ: Ablex.

Lash, Scott

1993 'Pierre Bourdieu: cultural economy and social change'. in Bourdieu: critical perspectives. C. Calhoun, E. LiPuma and M. Postone (eds.), 193-211. Cambridge: Polity

Lave, Jean and Wenger, Etienne

1991 Situated learning: legitimate peripheral participation. Cambridge: Cambridge University Press.

LiPuma, Edward

1993 'Culture and the concept of culture in a theory of practice'. in Bourdieu: critical perspectives. C. Calhoun, E. LiPuma and M. Postone (eds.), 14-34. Cambridge: Polity.

Lojkine, Jean

1986 'From the industrial revolution to the computer revolution: First signs of a new combination of material and human productive forms'. Capital and Class 29 : pp 111-129 
Morais, Ana, Fernanda Fontinhas, and Isabel Neves

1992 'Recognition and realisation rules in acquiring school science - the contribution of pedagogy and social background of students'. British Journal of Sociology of Education 13(2): 247-270

Mutch, Alistair

$2000 \mathrm{a}$ 'Trends and tensions in public house management'. International Journal of Hospitality Management 19(4): 361-374.

Mutch, Alistair

$2000 \mathrm{~b}$ 'Information literacy in organisations: a critical realist approach' in Information literacy: advances in programs and research. C. Bruce and $\mathrm{P}$. Candy (eds.) New South Wales, Australia: Charles Sturt University.

Mutch, Alistair

2000c 'Managers, information and teams: a tale of two companies'. The New Review of Information Behaviour Research 1: 151-166.

Mutch, Alistair

2001 'Where do public house managers come from? Some survey evidence'. International Journal of Contemporary Hospitality Management 13(2): 8692.

Mutch, Alistair

2002 'Applying the ideas of Bernstein to in-company education'. Management Learning 33(2):181-196.

Preece, David, Gordon Steven, and Valerie Steven 1999 Work, change and competition: managing for Bass. London: Routledge. Reay, Diane 
1995 "They Employ Cleaners to Do that': habitus in the primary classroom'. British Journal of Sociology of Education 16(3): 353-371.

Sadovnik, Alan R.

1995 Knowledge and pedagogy: the sociology of Basil Bernstein. Norwood, NJ:

Ablex.

Savage, Mike, James Barlow, Peter Dickens, and Tony Fielding

1992 Property, bureaucracy and culture: middle-class formation in contemporary Britain. London: Routledge.

Smith, Dennis

2001 'Organizations and humiliation: looking beyond Elias'. Organization 8(3): 537560.

Smith, Michael

1981 The pub and the publican: a participant observer study of a public house, Salford: Centre for Leisure Studies, University of Salford,

Stones, Rob

1996 Sociological reasoning: towards a past-modern sociology. Basingstoke: Macmillan.

Thompson, Paul

1988 'Playng at being skilled men: factory culture and pride in work skills among Coventry car workers'. Social History 13(1): 45-69.

Von Krogh, Georg, Kazuo Ichijo, and Ikujiro Nonaka

2000 Enabling knowledge creation: how to unlock the mystery of tacit knowledge and release the power of innovation. Oxford: Oxford University Press.

Walsham, Geoff 
2001 Making a world of difference: IT in a global context. Oxford: Oxford University Press.

Waquant, Loic J. D.

1993 'On the tracks of symbolic power: prefatory notes to Bourdieu's 'State Nobility". Theory, Culture and Society 10: 1-17.

Warde, Alan, Lydia Martens, and Wendy Olsen

1999, 'Consumption and the problem of variety: cultural omnivorousness, social distinction and dining out'. Sociology, 33(1): 105-127.

Watson, Tony and Pauline Harris

1999 The emergent manager. London: Sage.

Wenger, Etienne

1999 Communities of practice: learning, meaning and identity. Cambridge:

Cambridge University Press.

Willis, Paul

1971 Learning to labour: how working class kids get working class jobs.

Farnborough: Saxon House.

Willmott, Robert

1999 'Structure, agency and the sociology of education: rescuing analytical dualism'. British Journal of the Sociology of Education 20(1): 5-21

Zuboff, Shoshana

1988 In the age of the smart machine: the future of work and power. London: Heinemann. 